\title{
Electrical and Dielectric Properties of Polyaniline and Polyaniline/Montmorillonite Nanocomposite Prepared by Solid Reaction Using Spectroscopy Impedance
}

\author{
Imene Bekri-Abbes and Ezzeddine Srasra \\ Laboratoire de Physico-Chimie des Matériaux Minéraux et leurs Applications, Centre National de Recherches en Sciences des \\ Matériaux, Borj Cedria, BP 95-2050, Hammam-Lif, Tunis, Tunisia \\ Correspondence should be addressed to Imene Bekri-Abbes; bekrimene@gmail.com
}

Received 20 August 2015; Revised 22 October 2015; Accepted 28 October 2015

Academic Editor: Victor M. Castaño

Copyright (C) 2015 I. Bekri-Abbes and E. Srasra. This is an open access article distributed under the Creative Commons Attribution License, which permits unrestricted use, distribution, and reproduction in any medium, provided the original work is properly cited.

\begin{abstract}
The combination of two components with uniform distribution in nanoscale is expected to facilitate wider applications of the material. In this study, polyaniline (PAn) and polyaniline/montmorillonite (Mt) nanocomposite were prepared by solid reaction using persulfate of ammonium as oxidant. The phase composition and morphology of the nanocomposite were characterized by FTIR, UV-visible spectroscopy, X-ray diffractometer, thermal gravimetric analysis, and scanning electron microscopy. The electrical and dielectric properties were determined using spectroscopy impedance. The analysis of UV-visible and FTIR spectroscopy demonstrated that aniline chloride has been polymerized into PAn in its conducting emeraldine form. Thermogravimetric analysis suggested that PAn chains intercalated in the clay host are more thermally stable than those of free PAn prepared by solid-solid reaction. Electrical measurements were carried out using the complex impedance technique in the frequency range of $10^{-2}$ to $10^{4} \mathrm{~Hz}$ at different temperatures. The ac conductivity data of different nanocomposites were analyzed as a function of frequency and temperature. It has been found that the incorporation of inorganic clay phase into polyaniline matrix has an effect on the electrical and dielectric properties of the nanomaterial.
\end{abstract}

\section{Introduction}

Polyaniline is one of the most interesting conducting polymers due to its environmental stability, ease in preparation, exciting electrochemical, optical, and electrical properties, microelectronics devices, biosensors, electrochromic displays, and chemical sensors [1-3]. The combination of conducting polymers with host materials having different characteristics opens a way to new hybrid materials showing novel properties. Also conformation of polymer chains in the interlayer spaces may enable further characterization of the polymer structure. Clays among other hosts are natural, abundant, and inexpensive minerals which have unique layered structure and high mechanical strength as well as high chemical resistance. The synthesis of polyaniline-clay nanocomposites is currently carried out by intercalation of the monomer followed by the polymerization in the clay interlayer $[4,5]$.
Kim and coworkers $[4,5]$ have synthesized polyanilinemontmorillonite nanocomposite using an emulsion intercalation method. Yang and Chen [6], on the other hand, have synthesized Pan-Mt nanocomposites with organically modified clays. The electrosynthesis of PAn/Mt nanocomposite has also been reported [7]. A process of intercalation, which is not used very frequently, is the so-called solid state reaction. The latter is a mechanochemical adsorption that occurs between powders in the solid state. The so-called solid-solid reaction is a mechanochemical adsorption that occurs between powders in the solid state [8]. Solid state intercalation can be split into two stages: the first one consists of the diffusion of guest species from the outer surfaces of guest solids and the second is based on the penetration of the guest species into the interlayer spaces. Solid state intercalation of organic guest species into layered vanadium phosphorus oxide [9], zeolites [10], 
and layered clay minerals $[11,12]$ has been reported as a way of utilizing host structures.

The preparation of PAn/Mt nanocomposite by solid reaction has been firstly reported by Yamamoto and coworkers [13]. It was shown that the kinetic of the solid reaction is more rapid than that carried out in solution.

On the other hand, impedance spectroscopy is an important technique in understanding the charge transport mechanism and in finding the nature of charge carriers in complex systems. This technique is very useful to characterize the electrical and dielectric properties related to the microstructure; it has been extensively used in many research areas such as condensed matter physics, glass science, material science, and polymer science $[14,15]$. The charge transport mechanism in conducting polymers has been recently investigated using a number of experimental methods like ac conductivity and dielectric constant [16].

Although there have been several reports on the preparation and characterization of PAn/Mt nanocomposites prepared by conventional solution method, no work was done to study electrical and dielectric properties of PAn and PAn/Mt powder prepared by solid reaction. Therefore, the present study aimed to investigate the electrical and dielectric properties of PAn and PAn/Mt prepared by this technique.

\section{Experimental}

2.1. Material and Reagents. The crude clay mineral was obtained from the region of Zaghouan in northeastern Tunisia. Purification and recuperation of the clay fraction have been carried out using standard protocol [17]. This sample has been the subject of several studies in our laboratory $[18,19]$. The crude sample contains quartz and calcite as major impurities. The presence of smectite was confirmed by the $d_{001}$ spacing of the sample after air drying, calcination at $600^{\circ} \mathrm{C}$ for $2 \mathrm{~h}$, and glycol treatment. By means of lithium test, it was found that it consisted essentially of Mt. The chemical composition of the Mt, determined by Atomic Absorption Spectrometer (AAS Vario), was found to be as follows: $50.1 \%$ $\mathrm{SiO}_{2}, 3.95 \% \mathrm{MgO}, 17.4 \% \mathrm{Al}_{2} \mathrm{O}_{3}, 0.2 \% \mathrm{~K}_{2} \mathrm{O}, 0.08 \% \mathrm{CaO}, 1.5 \%$ $\mathrm{Na}_{2} \mathrm{O}, 6.3 \%\left(\mathrm{Fe}_{2} \mathrm{O}_{3+} \mathrm{FeO}\right)$, and $20.4 \%$ as loss on ignition. The cation exchange capacity (CEC) of the montmorillonite determined by $\mathrm{Cu}$ (II) ethylenediamine complex is about $100 \mathrm{Meq} / 100 \mathrm{~g}$. The sample has a BET specific surface area (Quantachrome, Autosorb I) of about $80 \mathrm{~m}^{2} / \mathrm{g}$. AnCl was purchased from Aldrich.

2.2. The Protocol of Preparation of PAn. PAn was synthesized by solid-solid reaction according to the following procedure; $\mathrm{AnCl}$ and APS with equimolar ratio were ground in an agate mortar until the color changed to dark green. The reaction takes 5 minutes to obtain a dark green color. Afterward, the dark green product was washed with distilled water until a colorless wash solution without oligomers was obtained.

2.3. The Protocol of Preparation of PAn/Mt Nanocomposite. The protocol of preparation of PAn/Mt nanocomposite is as follows: $0.5 \mathrm{~g}$ of $\mathrm{Mt}$ has been ground with $\mathrm{AnCl}$ (the molar

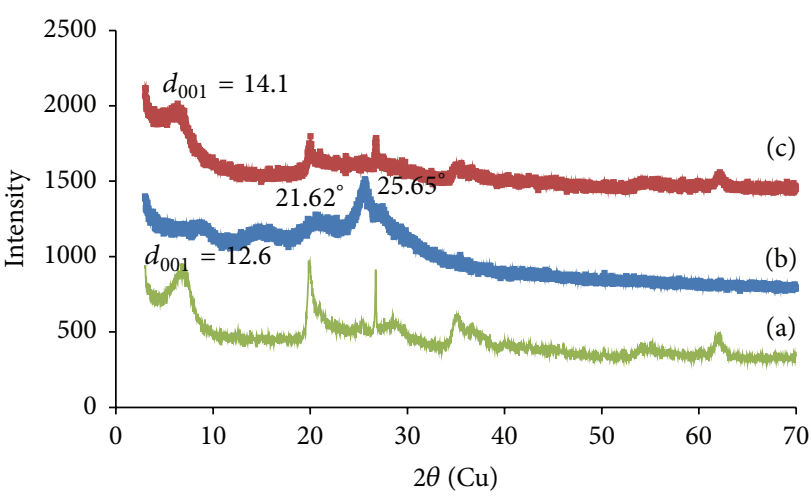

FIgure 1: DRX of (a) Mt, (b) PAn, and PAn/Mt nanocomposite.

ratio of $\mathrm{AnCl}$ is equal to $3 \mathrm{CEC}$ ) for 10 minutes then APS has been added and the mixture is ground for 7 minutes until the change of color to dark green, which is the characteristic color of emeraldine polyaniline. The molar ratio of oxidant/aniline is 1.25 . The dark green nanocomposite was washed with distilled water until colorless oligomer-free wash water was produced.

2.4. Characterization Techniques. The structure was examined by X-ray diffraction using a PANalytical X-ray diffractometer using $\mathrm{Cu}$ radiation. The IR spectra were collected with a Nicolet spectrophotometer model 560 using a scanning range from 400 to $4000 \mathrm{~cm}^{-1}$. Samples were prepared as KBr pellet. The electronic structure of the nanocomposite was determined from UV-vis absorption spectrum in dimethylformamide (DFM) solution on a PerkinElmer (model Lambda 20) spectrophotometer. The SEM images were obtained by a JSM-5400 scanning electron microscope (JEOL). A fine gold coat has been deposited on the samples under vacuum in a JFC-1100 sputter coater (JEOL). Thermogravimetry analysis was performed using a SETARAM instrument at a heating rate of $10^{\circ} \mathrm{C} / \mathrm{min}$ in an air atmosphere. The electrical conductivity of different samples was prepared as pellet form under a pressure of $5 \mathrm{Mg} / \mathrm{cm}^{2}$ and coated on both sides with silver paint using a Hewlett Packard model 4192A impedance analyzer.

\section{Results and Discussion}

\subsection{Structure Characterization}

3.1.1. XRD Analysis. Figure 1 shows the XRD patterns of Mt, $\mathrm{PAn}$, and PAn/Mt nanocomposite. The basal spacing of $\mathrm{Mt}$ is $1.26 \mathrm{~nm}$ corresponding to $\mathrm{Na}^{+}$exchanged Mt. A basal distance around $1.41 \mathrm{~nm}$ can be attributed to PAn/Mt nanocomposite.

Taking into account the thickness of the silicate layer (about 9.6 $\AA$ ), an interlayer expansion of $0.45 \mathrm{~nm}$ was obtained for PAn/Mt nanocomposite. This expansion is in agreement with a single chain of PAn with extended conformation within the clay interlayer. The X-ray diffraction pattern of PAn shows the appearance of two principal peaks at $2 \theta \approx 21^{\circ}$ 

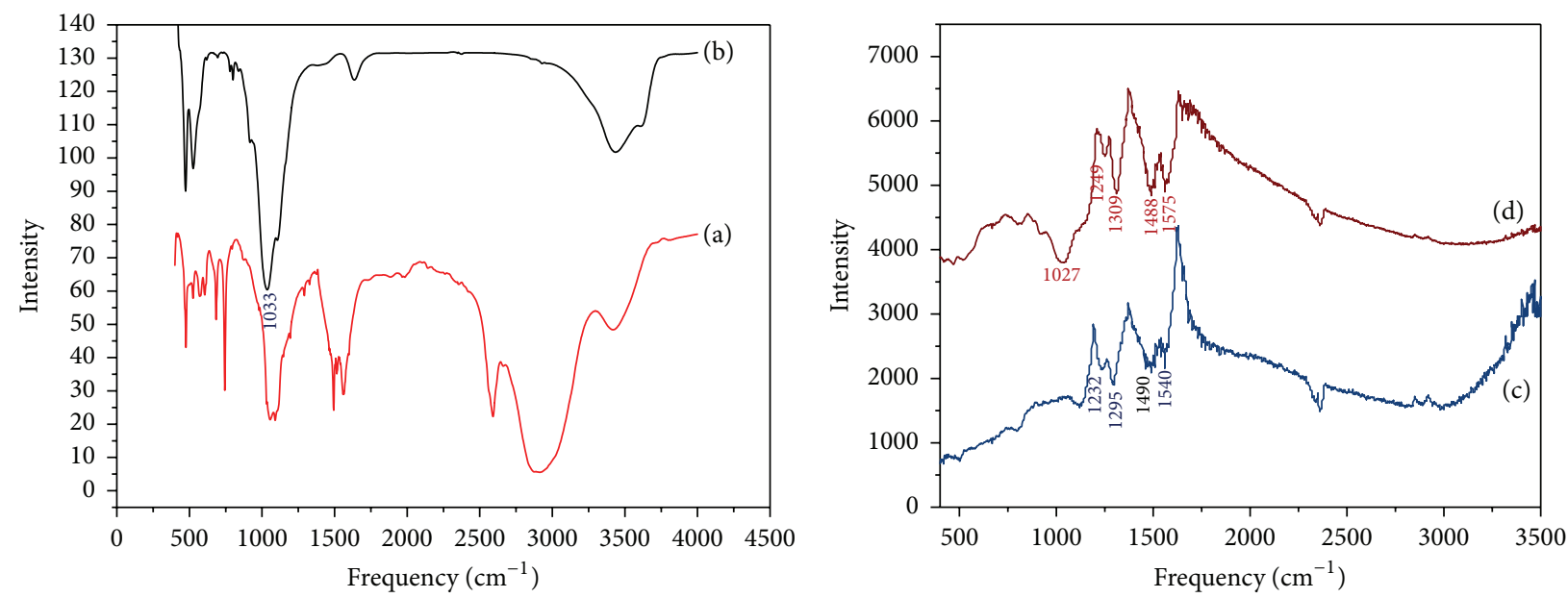

Figure 2: FTIR spectra of (a) AnCl, (b) Mt, (c) PAn, and (d) PAn/Mt nanocomposite.

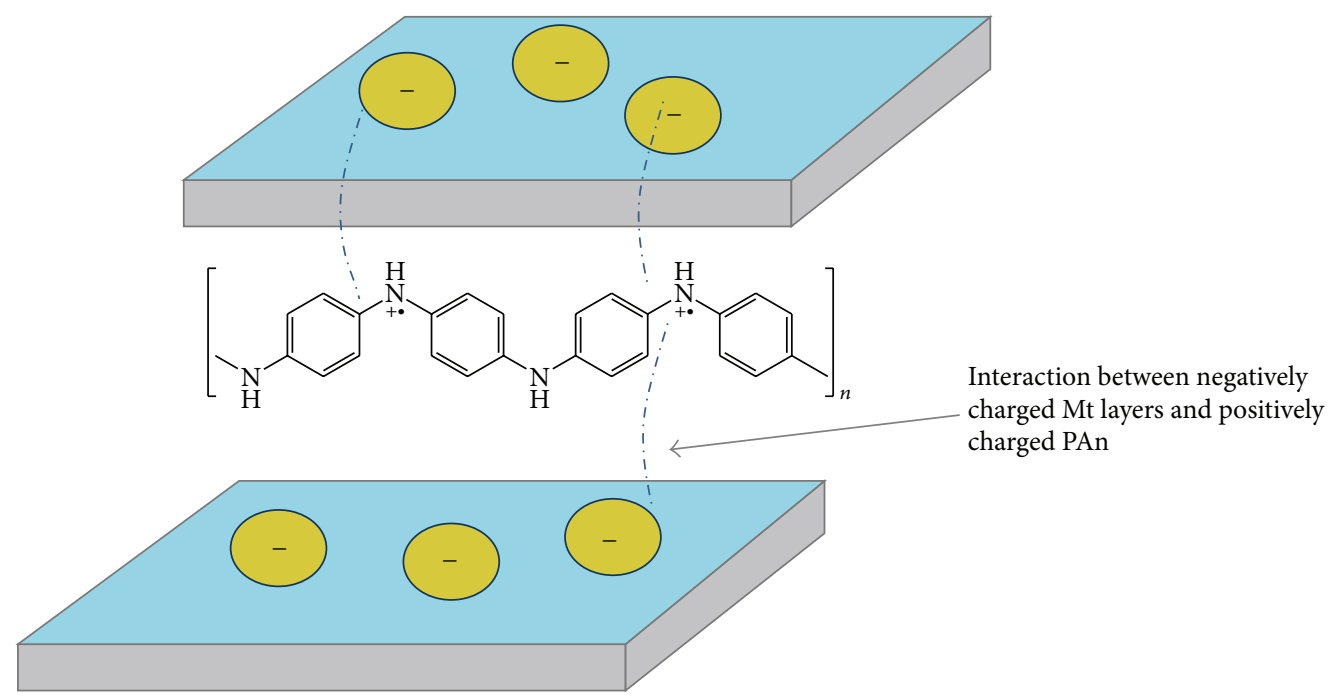

FIgURE 3: Schematic representation of the interaction between PAn chains and Mt layers.

and $25^{\circ}$ and which can be attributed to the periodicity parallel and perpendicular to the polymer chain, respectively [20].

3.1.2. FTIR Spectroscopy. Figure 2 presents the FTIR spectra of An, Mt, PAn, and PAn/Mt nanocomposite. The IR spectrum of MMT (Figure 2(b)) showed the following bands: $v$ $\mathrm{OH}$ of $\mathrm{H}_{2} \mathrm{O} \sim 3446 \mathrm{~cm}^{-1}$ and $\delta \mathrm{OH}$ at $1643 \mathrm{~cm}^{-1}$.

The bands at $1033 \mathrm{~cm}^{-1}$ are assigned to $\mathrm{Si}-\mathrm{O}$ stretching vibration. On the other hand, the infrared spectrum of $\mathrm{AnCl}$ (Figure 2(a)) presents essentially the bands at 1564 and $1494 \mathrm{~cm}^{-1}$ which correspond to N-H stretching vibration [21].

The spectrum of PAn (Figure 2(c)) indicates the presence of four characteristic peaks at $1575 \mathrm{~cm}^{-1}, 1488 \mathrm{~cm}^{-1}$, $1295 \mathrm{~cm}^{-1}$, and $1249 \mathrm{~cm}^{-1}$. These bands agree with literature data of polyaniline in its protonated conducting form [22].

The main peaks around $1566-1578 \mathrm{~cm}^{-1}$ and $1476-$ $1478 \mathrm{~cm}^{-1}$ correspond to stretching deformations of a quinoid diimine unit and a benzenoid diamine unit, respectively [23]. After the grinding of $\mathrm{AnCl}$ with $\mathrm{Mt}$ and the adding of oxidant, we have noticed that the absorption bands of Mt are weakened and masked partially by an emerging strong electronic band, which starts from $1800 \mathrm{~cm}^{-1}$ and extends to the visible region. This band results from the electronic structure of conducting polymer and is due to free-charge carrier absorption.

Moreover, the appearance of characteristic bands of PAn in the spectrum of the nanocomposite with a slight shift indicating the presence of interaction between Mt and PAn can be seen. This is suggested to be due to the Coulomb interaction between the positive charge of nitrogen in the polymer and the partially negatively charged surface of the clay as represented in Figure 3.

3.1.3. UV-Visible Spectroscopy. UV-visible spectra of PAn and PAn/Mt nanocomposite are shown in Figure 4. The two spectra showed the appearance of two peaks at 313-331 and 603$613 \mathrm{~nm}$. These peaks correspond to $\pi-\pi^{*}$ transition of benzenoid rings and the excitation absorption of the quinoid rings of the emeraldine base, respectively [18]. 


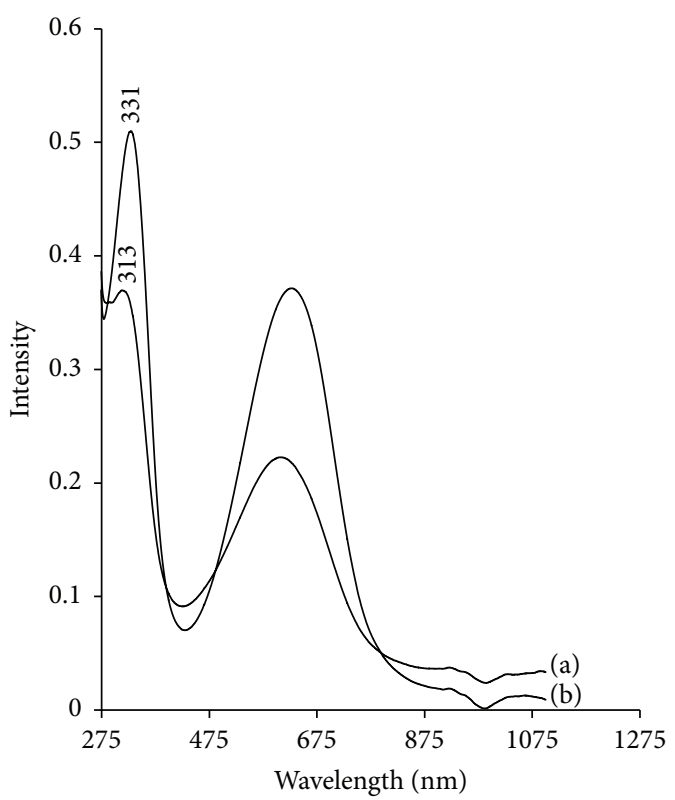

Figure 4: UV-visible spectroscopy of (a) PAn and (b) Mt/PAn nanocomposite.

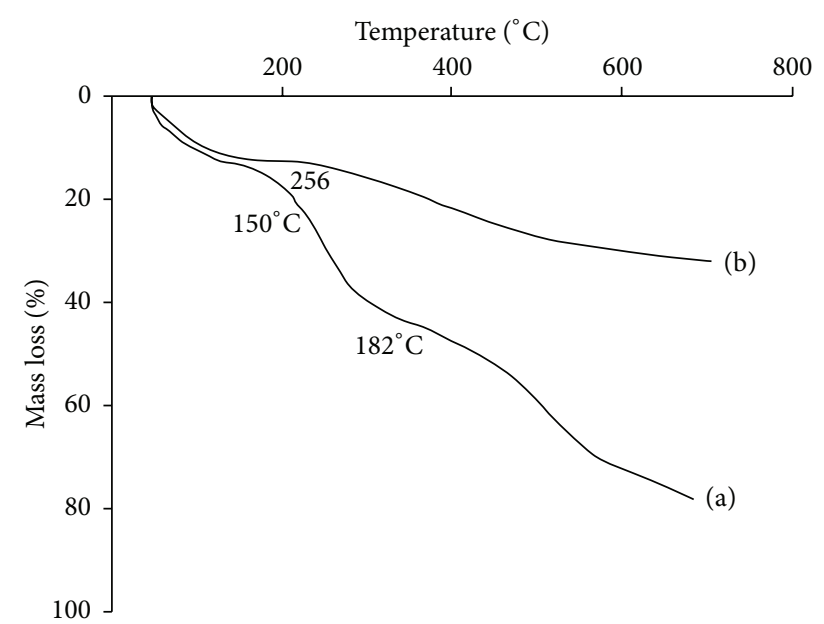

Figure 5: TGA curves of (a) PAn and (b) PAn/Mt nanocomposite.

3.1.4. Thermal Gravimetric. Plots shown in Figure 5 represent the thermal gravimetric curves of PAn and PAn/Mt nanocomposite. TGA curve of PAn presented three stages of weight loss. The first stage close to $150^{\circ} \mathrm{C}$ was mainly due to the removal of free water, while the second one ranging from 182 to $305^{\circ} \mathrm{C}$ was ascribed to the elimination of $\mathrm{Cl}$ dopants and the third one starting at about $400^{\circ} \mathrm{C}$ can be attributed to the thermal decomposition of PAn backbone chains [24]. The incorporation of $\mathrm{Mt}$ sheets in the polymer chains ameliorates its thermal stability by $105^{\circ} \mathrm{C}$ relative to bulk PAn and this can be attributed to the Mt nanosheets acting as barriers for the degradation of PAn chains.

3.1.5. SEM Characterization. Figure 6 shows SEM micrographs of PAn and PAn/Mt nanocomposite. From the SEM micrographs, PAn has a granular texture as shown in Figure 6(b) and Mt has a flaky texture reflecting its layered structure (Figure 6(a)). It can be clearly seen in Figure 6(c) that textures of both PAn and Mt are retained in the nanocomposites. It should be noted that most of the PAn chains are intercalated into the interlayer spacing of Mt based on the XRD data.

\subsection{Electrical and Dielectric Properties}

3.2.1. Impedance Spectroscopy. When a semiconductor system is perturbed by a small electrical voltage, its impedance $Z(\omega)$, which is a complex number, can be represented by the following equation:

$$
Z(\omega)=\operatorname{Re}(Z(\omega))+i \operatorname{Im}(Z(\omega))
$$

where $\operatorname{Re}(Z(\omega))$ and $\operatorname{Im}(Z(\omega))$ are the real and imaginary part of the impedance, respectively.

The Nyquist plot is used to describe the relationship between $\operatorname{Re}(Z(\omega))$ and $\operatorname{Im}(Z(\omega))$. It is represented by imaginary part $(-\operatorname{Im}(Z(\omega)))$ versus the real part $(\operatorname{Re}(Z(\omega)))$ where the angular frequency $(\omega)$ increases from the right to the left.

The relationship between the real part and imaginary part in the Nyquist can be illustrated by several electrical circuits. The Nyquist diagrams of PAn and PAn/Mt for different temperatures are shown in Figure 7.

The presence of a single semicircle and the shift of its center along the real axis indicate that the material can be illustrated by an electrochemical cell represented by equivalent circuit of a resistance $(R)$ parallel to a capacitor $(C)$. This electrical behavior proved that such an electrical circuit is a simpler representation of an amorphous semiconductor in which charge transport occurs through hopping. As these semicircles are most commonly depressed, it is better to replace the capacitor with a constant phase element (CPE). The equivalent circuit can be expressed by a parallel connection of an ohmic resistor $R_{\mathrm{gb}}$ and a CPE.

3.2.2. ac Conductivity. The frequency-dependent conductivity $\sigma(\omega)$ for PAn and PAn/Mt nanocomposite for different temperatures is shown in Figure 8. For all temperatures and for the two samples, $\sigma(\omega)$ is independent of $\omega$ in lowfrequency regions and almost equal to the direct-current (dc) conductivity. Then, the ac conductivity starts to increase. This trend in conductivity is similar to common electrical behavior of disordered materials. It is well known that, for disordered semiconductivity, the real part of the ac conductivity can be represented by the following forms [25]:

$$
\begin{aligned}
& \sigma_{\mathrm{ac}}(\omega)=\sigma_{\mathrm{dc}} \quad\left(\omega<\omega_{c}\right), \\
& \sigma_{\mathrm{ac}}(\omega)=A \omega^{s} \quad\left(\omega>\omega_{c}\right) .
\end{aligned}
$$

$A$ is the electrode area coated on the surfaces of the samples and $s$ is the frequency exponent which generally is less than or equal to one $(0 \leq s \leq 1)$. The transition from one regime to the other is marked by a frequency $\omega_{c}$. 


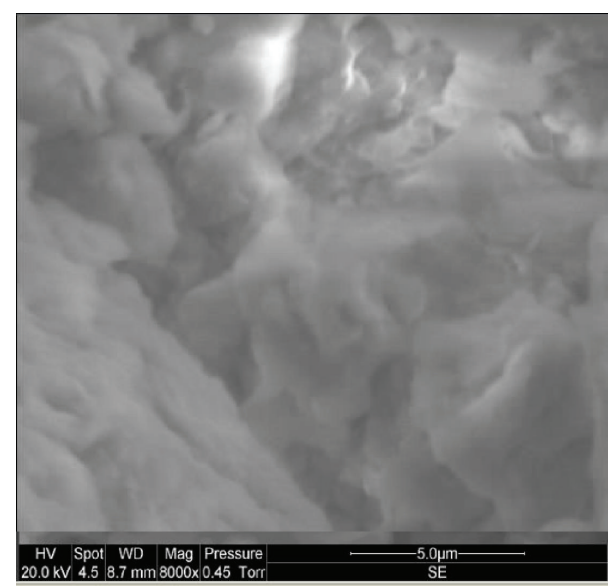

(a)

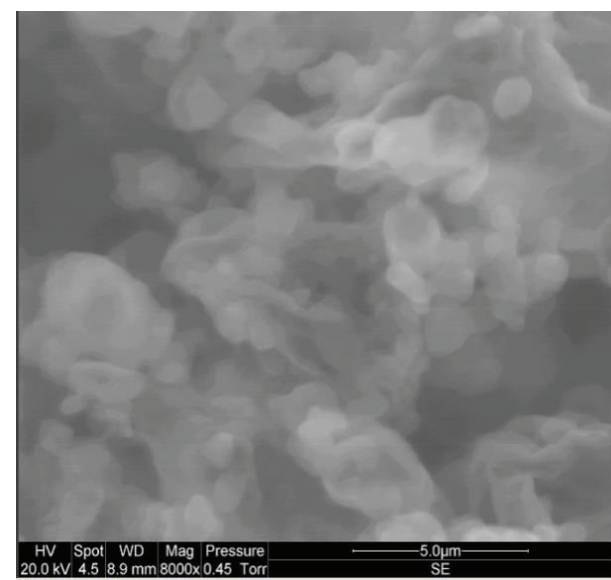

(b)

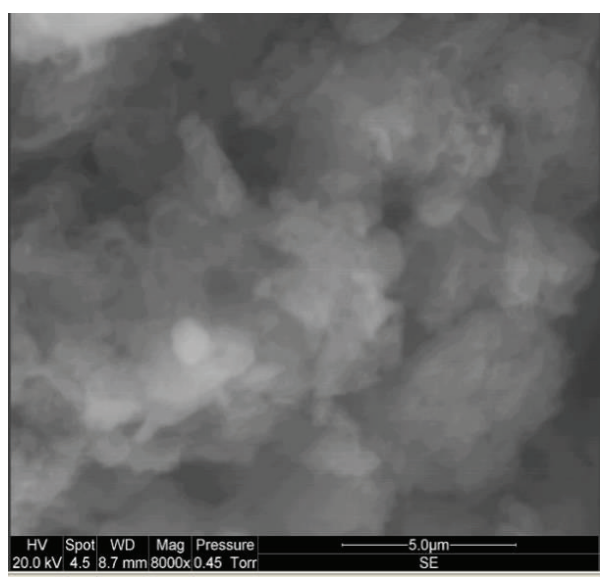

(c)

Figure 6: SEM micrographs of (a) Mt, (b) PAn, and (c) PAn/Mt nanocomposite.

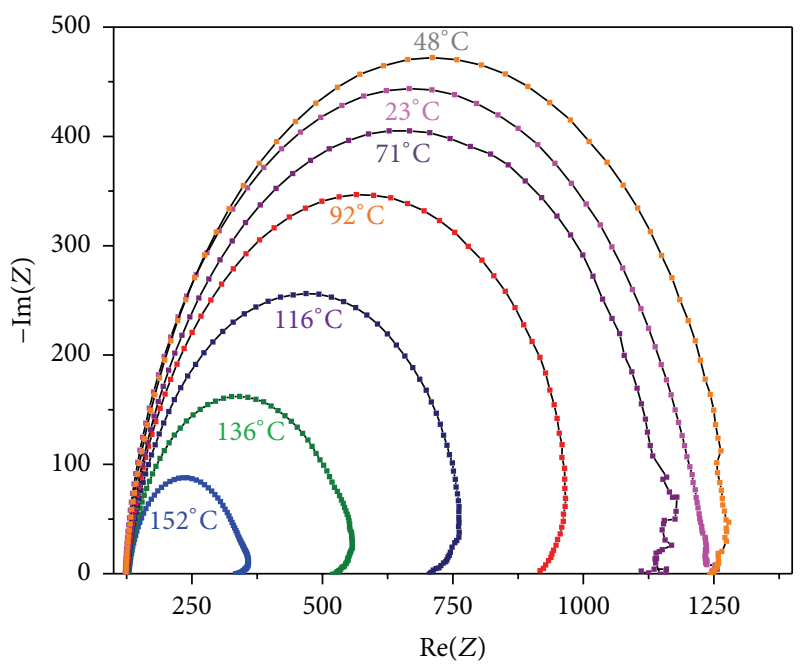

(a)

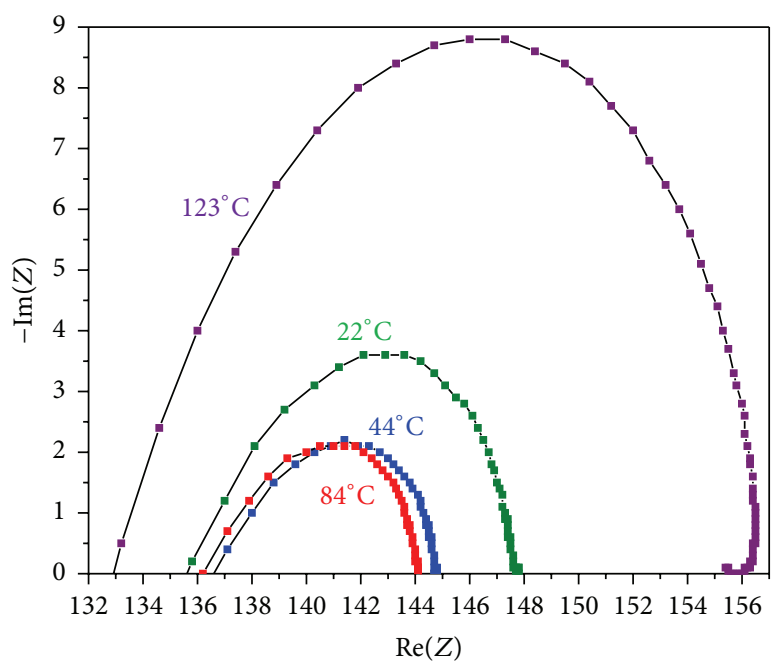

(b)

FIGURE 7: Complex impedance plane (Nyquist) plots for (a) PAn and (b) PAn/Mt nanocomposite for different temperatures. 


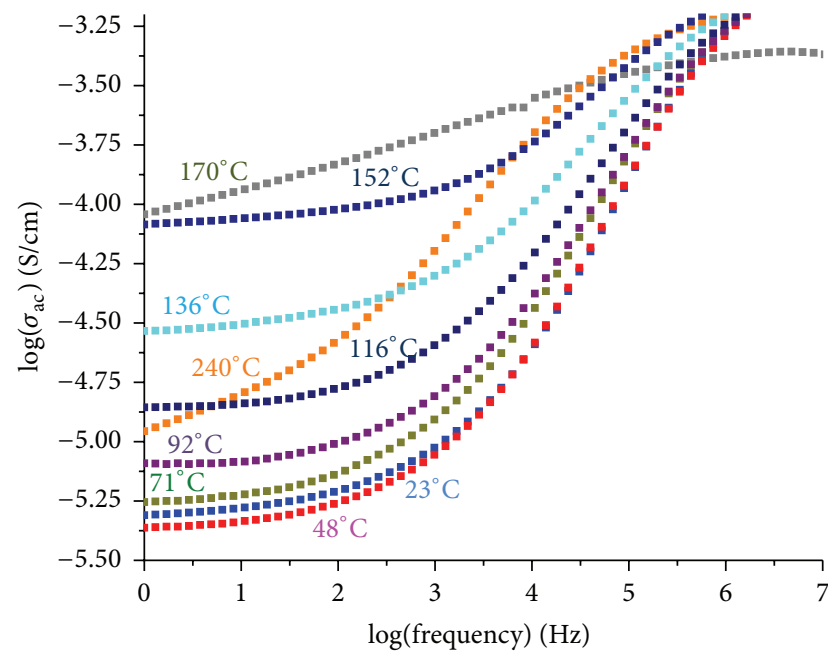

(a)

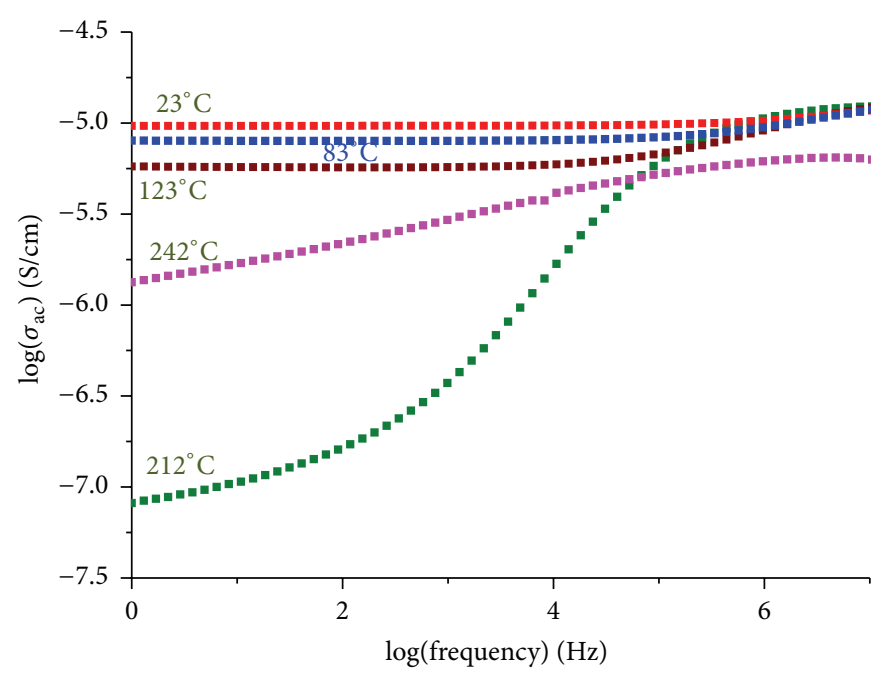

(b)

FIgURE 8: ac conductivity spectra of (a) PAn and (b) PAn/Mt nanocomposite for different temperatures.

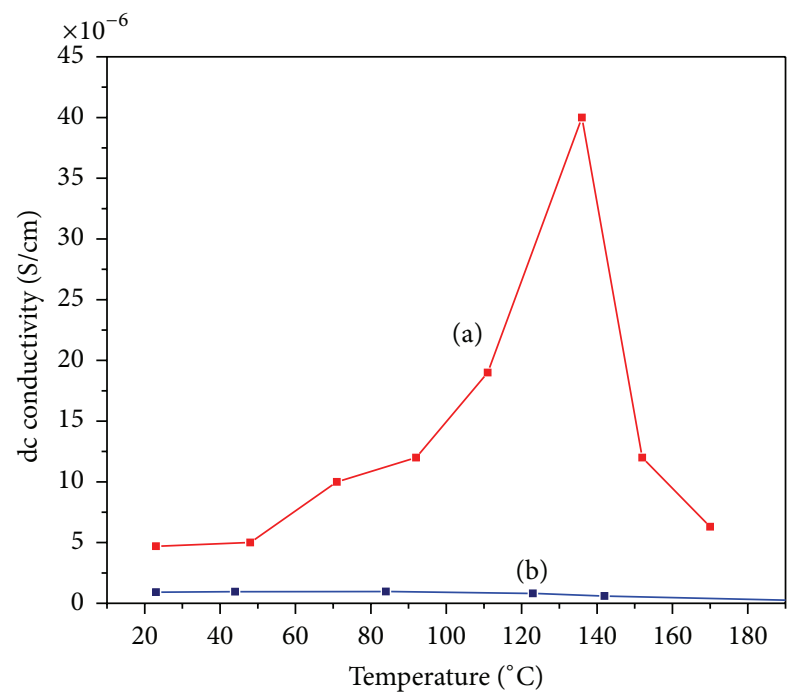

FIGURE 9: dc conductivity versus temperature for (a) PAn and (b) $\mathrm{PAn} / \mathrm{Mt}$ nanocomposite.

3.2.3. dc Conductivity. The variation of the dc conductivity, $\sigma_{\mathrm{dc}}$, with temperature for PAn and PAn/Mt nanocomposite is represented in Figure 9. The observed increase in $\sigma_{\mathrm{dc}}$ with temperature indicates semiconductor behavior of PAn sample. In addition, the dc conductivity is smaller in the case of PAn/Mt nanocomposite. The plots show the decrease in the electrical conductivity of PAn when being mixed with the Mt. This can be attributed to the presence of insulating Mt phase in the case of the nanocomposite [26, 27]. Another explanation for the decrease of conductivity could be due to the coulomb interaction with clay layer which could affect the delocalization on PAn chains. The same observation has been detected when exposing PAn powder to ethanol vapor. A decrease of conductivity resulting from the decrease in the conjugation length has been noted as a result of the formation of H-bonding between the -OH group of ethanol and both the amine and imine group of PAn [28].

The conductivity of PAn was decreased when incorporating Mt; however, the thermal stability of PAn was improved as reflected from TGA plots. The improved thermal stability was also confirmed from Figure 9 where the dc conductivity of PAn/Mt nanocomposite was studied over the range of 23$220^{\circ} \mathrm{C}$. In this way, PAn attains thermal stability when being mixed with Mt.

3.2.4. Dielectric Constant. Figure 10 shows the frequency dependence of dielectric constant at different temperatures for PAn/Mt nanocomposite and PAn. These figures are plotted on a log-log scale because of high values of dielectric constant obtained at low frequencies. The values of dielectric constant for the two samples are very high at low frequencies and high temperatures and then decrease with increasing frequency. Such high values of dielectric constant may be due to the interfacial effects within the bulk of the samples and also may be partially due to the electrode effects. At high frequencies, the periodic reversal of the electric field occurs so fast that ion diffusion in the direction of the field can no longer follow the field variation. Consequently, the polarization due to the charge accumulation decreases, leading to a decrease in the values of dielectric constant.

The values of dielectrics constants increase when incorporating Mt phase. The presence of inorganic Mt could be the reason behind such increase. Comparable behavior has been attained for polyaniline when incorporating $\mathrm{TiO}_{2}$ nanocomposites and it has been attributed to the interface between polyaniline and $\mathrm{TiO}_{2}$ which plays an important role in yielding a large dielectric constant in the nanocomposite [29]. By the same way, dielectric constants of polyaniline increased 100-150 times compared to plain polyaniline matrix when incorporating $\delta \mathrm{Fe}_{2} \mathrm{O}_{3}$ nanoparticles to the polymer matrix [30]. 


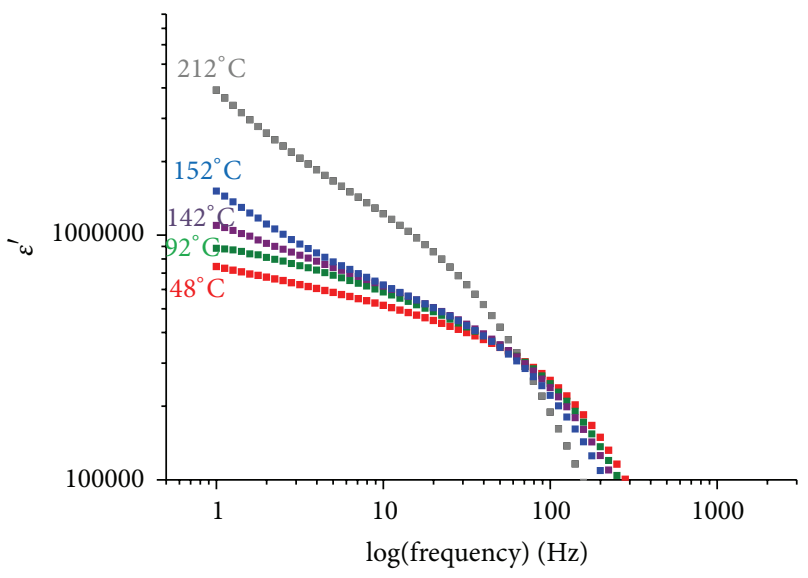

(a)

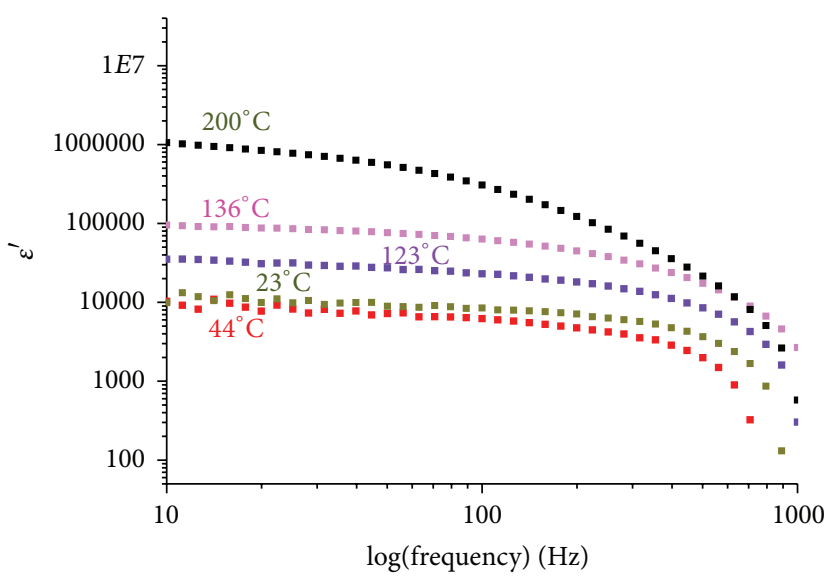

(b)

Figure 10: Logarithmic plots of dielectric constant for (a) PAn/Mt and (b) PAn.

\section{Conclusion}

PAn and PAn/Mt nanocomposite were successfully synthesized by solid state reaction. The results of XRD, FTIR spectra, and SEM proved the formation of intercalated structure within MMT interlayer. From UV-visible and FTIR spectroscopy characterization, we have confirmed the formation of the emeraldine form of polyaniline. The TGA results revealed an enhancement in the thermal stability for the PAnMMT nanocomposite relative to pure PAn. Electrical and dielectric properties have been studied using spectroscopy impedance. The ac conductivity of the nanocomposite shows the same behavior of common disordered material. It shows a regime of constant dc conductivity at low frequencies and a crossover to a frequency-dependent regime of the type $A \omega^{s}$ at high frequencies. The low frequency conductivity of the nanocomposite is low compared to free PANI; these results are explained by the low content of polymer in the inorganic matrix and the disruption of the three-dimensional organization of the polymer chains. The values of dielectrics constants increase when incorporating Mt phase.

\section{Conflict of Interests}

The authors declare that there is no conflict of interests regarding the publication of this paper.

\section{Acknowledgment}

The authors gratefully acknowledge the financial support provided by Higher Education and Scientific Research sector of the Ministry of Higher Education, Scientific Research and Information and Communication Technologies of Tunisia.

\section{References}

[1] E. M. Genies, P. Hany, and C. J. Santier, "A rechargeable battery of the type polyaniline/propylene carbonate- $\mathrm{LiClO}_{4} / \mathrm{Li}$ Al," Journal of Applied Electrochemistry, vol. 18, no. 5, pp. 751756, 1988.
[2] Y. Wang, H. Wei, J. Wang et al., "Electropolymerized polyaniline/manganese iron oxide hybrids with an enhanced color switching response and electrochemical energy storage," Journal of Materials Chemistry A, vol. 3, no. 41, pp. 20778-20790, 2015.

[3] L. W. Shacklette, R. R. Chance, D. M. Ivory, G. G. Miller, and R. H. Baughman, "Electrical and optical properties of highly conducting charge-transfer complexes of poly(p-phenylene)," Synthetic Metals, vol. 1, no. 3, pp. 307-320, 1980.

[4] B.-H. Kim, J.-H. Jung, S.-H. Hong et al., "Nanocomposite of polyaniline and $\mathrm{Na}^{+}$-montmorillonite clay," Macromolecules, vol. 35, no. 4, pp. 1419-1423, 2002.

[5] B. H. Kim, J. H. Jung, J. W. Kim, H. J. Choi, and J. Joo, "Physical characterization of polyaniline- $\mathrm{Na}^{+}$-montmorillonite nanocomposite intercalated by emulsion polymerization," Synthetic Metals, vol. 117, no. 1-3, pp. 115-118, 2001.

[6] S. M. Yang and K. H. Chen, "Synthesis of polyaniline-modified montmorillonite nanocomposite," Synthetic Metals, vol. 135-136, pp. 51-52, 2003.

[7] B. Feng, Y. Su, J. Song, and K. Kong, "Electropolymerization of polyaniline/montmorillonite nanocomposite," Journal of Materials Science Letters, vol. 20, no. 4, pp. 293-294, 2001.

[8] G. Rothenberg, A. P. Downie, C. L. Raston, and J. L. Scott, "Understanding solid/solid organic reactions," Journal of the American Chemical Society, vol. 123, no. 36, pp. 8701-8708, 2001.

[9] K. Lázár, G. Pál-Borbèly, H. K. Beyer, and H. G. Karge, "Solidstate ion exchange in zeolites. Part 5- $\mathrm{NH}_{4}$-Y-iron(II) chloride," Journal of the Chemical Society, Faraday Transactions, vol. 90, no. 9, pp. 1329-1334, 1994.

[10] S. Yariv and I. Lapides, "The effect of mechanochemical treatments on clay minerals and the mechanochemical adsorption of organic materials onto clay minerals," Journal of Materials Synthesis and Processing, vol. 8, no. 3, pp. 223-233, 2000.

[11] N. Khaorapapong, K. Kuroda, H. Hashizume, and M. Ogawa, "Solid-state intercalation of 4,4'-bipyridine and 1,2-di(4pyridine)ethylene into the interlayer spaces of $\mathrm{Co}(\mathrm{II})-, \mathrm{Ni}(\mathrm{II})$ and $\mathrm{Cu}(\mathrm{II})$-montmorillonites," Applied Clay Science, vol. 19, no. $1-6$, pp. 69-76, 2001.

[12] A. Landau, A. Zaban, I. Lapides, and S. Yariv, "Montmorillonite treated with rhodamine-6G mechanochemically and in aqueous suspensions," Journal of Thermal Analysis and Calorimetry, vol. 70, no. 1, pp. 103-113, 2002. 
[13] N. Yamamoto, T. Okuhara, and T. Nakato, "Intercalation compound of $\mathrm{VOPO}_{4} \cdot 2 \mathrm{H}_{2} \mathrm{O}$ with acrylamide: preparation and exfoliation," Journal of Materials Chemistry, vol. 11, no. 7, pp. 1858-1863, 2001.

[14] P. R. Prezas, M. J. Soares, F. N. A. Freire, and M. P. F. Graça, "Structural, electrical and dielectric characterization of $\mathrm{TeO}_{2}-\mathrm{WO}_{3}-\mathrm{Y}_{2} \mathrm{O}_{3}-\mathrm{Er}_{2} \mathrm{O}_{3}-\mathrm{Yb}_{2} \mathrm{O}_{3}$ glasses," Materials Research Bulletin, vol. 68, pp. 314-319, 2015.

[15] R. Rajan, N. A. N. Raj, S. Madeswaran, and D. R. Babu, "Dielectric studies on struvite urinary crystals, a gateway to the new treatment modality for urolithiasis," Spectrochimica Acta Part A: Molecular and Biomolecular Spectroscopy, vol. 148, pp. 266-270, 2015.

[16] M. Krichen, M. Megdiche, K. Guidara, and M. Gargouri, "AC conductivity and mechanism of conduction study of lithium barium pyrophosphate $\mathrm{Li}_{2} \mathrm{BaP}_{2} \mathrm{O}_{7}$ using impedance spectroscopy," Ionics, vol. 21, no. 4, pp. 935-948, 2015.

[17] H. Van Olphen, An Introduction to Clay Colloid Chemistry, Interscience, New York, NY, USA, 1963.

[18] I. Bekri-Abbes and E. Srasra, "Characterization and AC conductivity of polyaniline-montmorillonite nanocomposites synthesized by mechanical/chemical reaction," Reactive and Functional Polymers, vol. 70, no. 1, pp. 11-18, 2010.

[19] I. Bekri-Abbes and E. Srasra, "Solid state polymerization and intercalation of aniline in Fe rich montmorillonite," Journal of Polymer Research, vol. 18, no. 4, pp. 691-699, 2011.

[20] J. P. Pouget, C.-H. Hsu, A. G. MacDiarmid, and A. J. Epstein, "Structural investigation of metallic PAN-CSA and some of its derivatives," Synthetic Metals, vol. 69, no. 1-3, pp. 119-120, 1995.

[21] G. A. Eimer, M. B. Gómez Costa, L. B. Pierella, and O. A. Anunziata, "Thermal and FTIR spectroscopic analysis of the interactions of aniline adsorbed on to MCM-41 mesoporous material," Journal of Colloid and Interface Science, vol. 263, no. 2, pp. 400-407, 2003.

[22] M. Zagorska, A. Prori, and S. Lefrant, "Spectroelectrochemistry and spectroscopy of conducting polymers," in Handbook of Organic Conductive Molecules and Polymers, H. S. Nalwa, Ed., vol. 3 of Conductive Polymers: Spectroscopy and Physical Properties, pp. 183-215, Wiley, London, UK, 1997.

[23] H. Gu, J. Guo, X. Zhang et al., "Giant magnetoresistive phosphoric acid doped polyaniline-silica nanocomposites," The Journal of Physical Chemistry C, vol. 117, no. 12, pp. 6426-6436, 2013.

[24] H. Gu, Y. Huang, X. Zhang et al., "Magnetoresistive polyanilinemagnetite nanocomposites with negative dielectrical properties," Polymer, vol. 53, no. 3, pp. 801-809, 2012.

[25] J. Bisquert and G. Garcia-Belmonte, "Interpretation of AC conductivity of lightly doped conducting polymers in terms of hopping conduction," Russian Journal of Electrochemistry, vol. 40, no. 3, pp. 352-358, 2004.

[26] G. Li, S. Yan, E. Zhou, and Y. Chen, "Preparation of magnetic and conductive NiZn ferrite-polyaniline nanocomposites with core-shell structure," Colloids and Surfaces A: Physicochemical and Engineering Aspects, vol. 276, no. 1-3, pp. 40-44, 2006.

[27] Y. Long, Z. Chen, J. L. Duvail, Z. Zhang, and M. Wan, "Electrical and magnetic properties of polyaniline $/ \mathrm{Fe}_{3} \mathrm{O}_{4}$ nanostructures," Physica B: Condensed Matter, vol. 370, no. 1-4, pp. 121-130, 2005.

[28] A. Choudhury, "Polyaniline/silver nanocomposites: dielectric properties and ethanol vapour sensitivity," Sensors and Actuators B: Chemical, vol. 138, no. 1, pp. 318-325, 2009.

[29] A. Dey, S. De, A. De, and S. K. De, "Characterization and dielectric properties of polyaniline- $\mathrm{TiO}_{2}$ nanocomposites," Nanotechnology, vol. 15, no. 9, pp. 1277-1283, 2004.
[30] N. N. Mallikarjuna, S. K. Manohar, P. V. Kulkarni, A. Venkataraman, and T. M. Aminabhavi, "Novel high dielectric constant nanocomposites of polyaniline dispersed with $\gamma-\mathrm{Fe}_{2} \mathrm{O}_{3}$ nanoparticles," Journal of Applied Polymer Science, vol. 97, no. 5, pp. 1868-1874, 2005. 

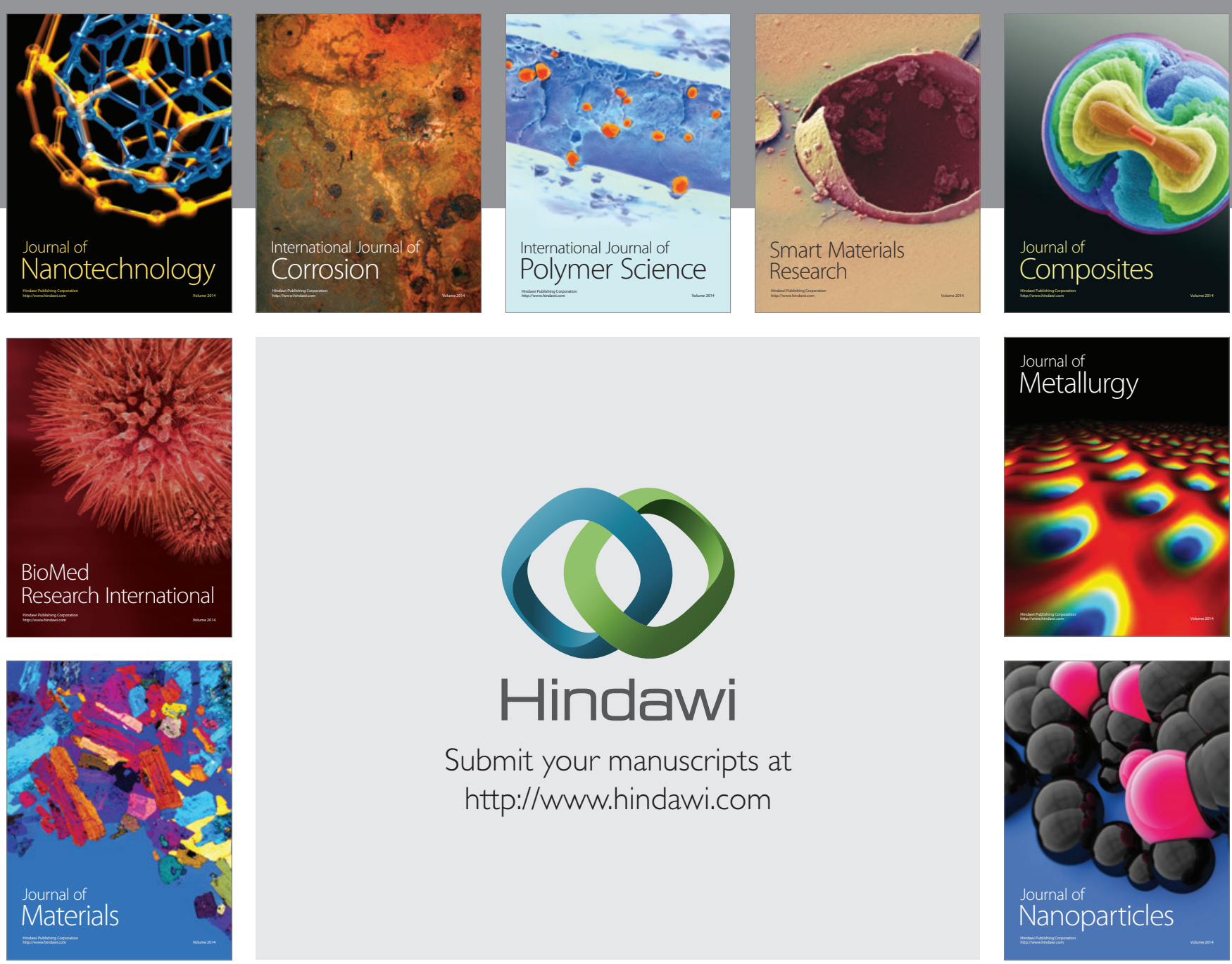

Submit your manuscripts at http://www.hindawi.com
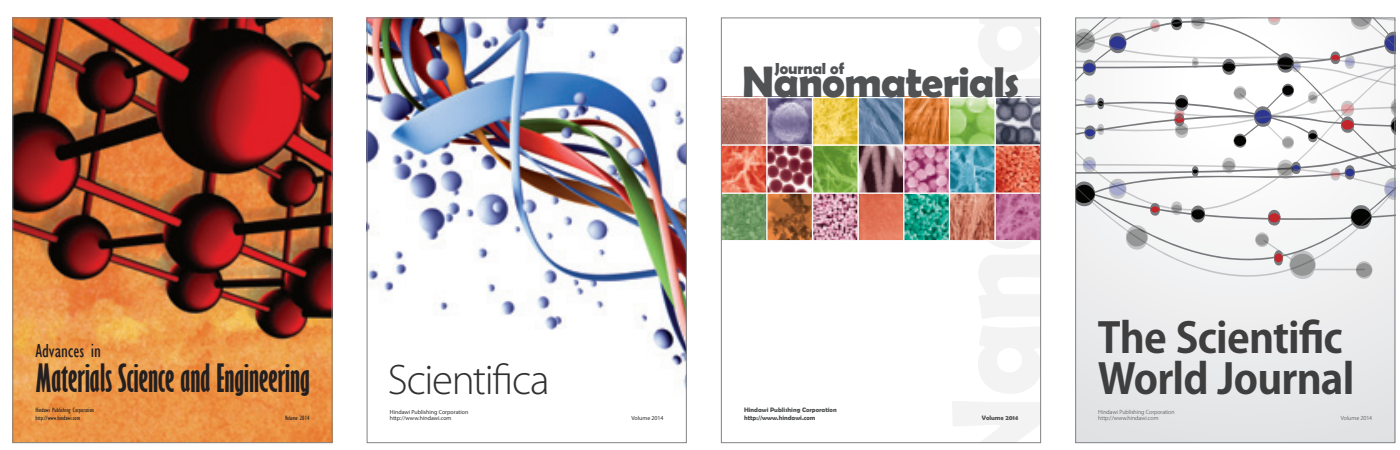

\section{The Scientific World Journal}
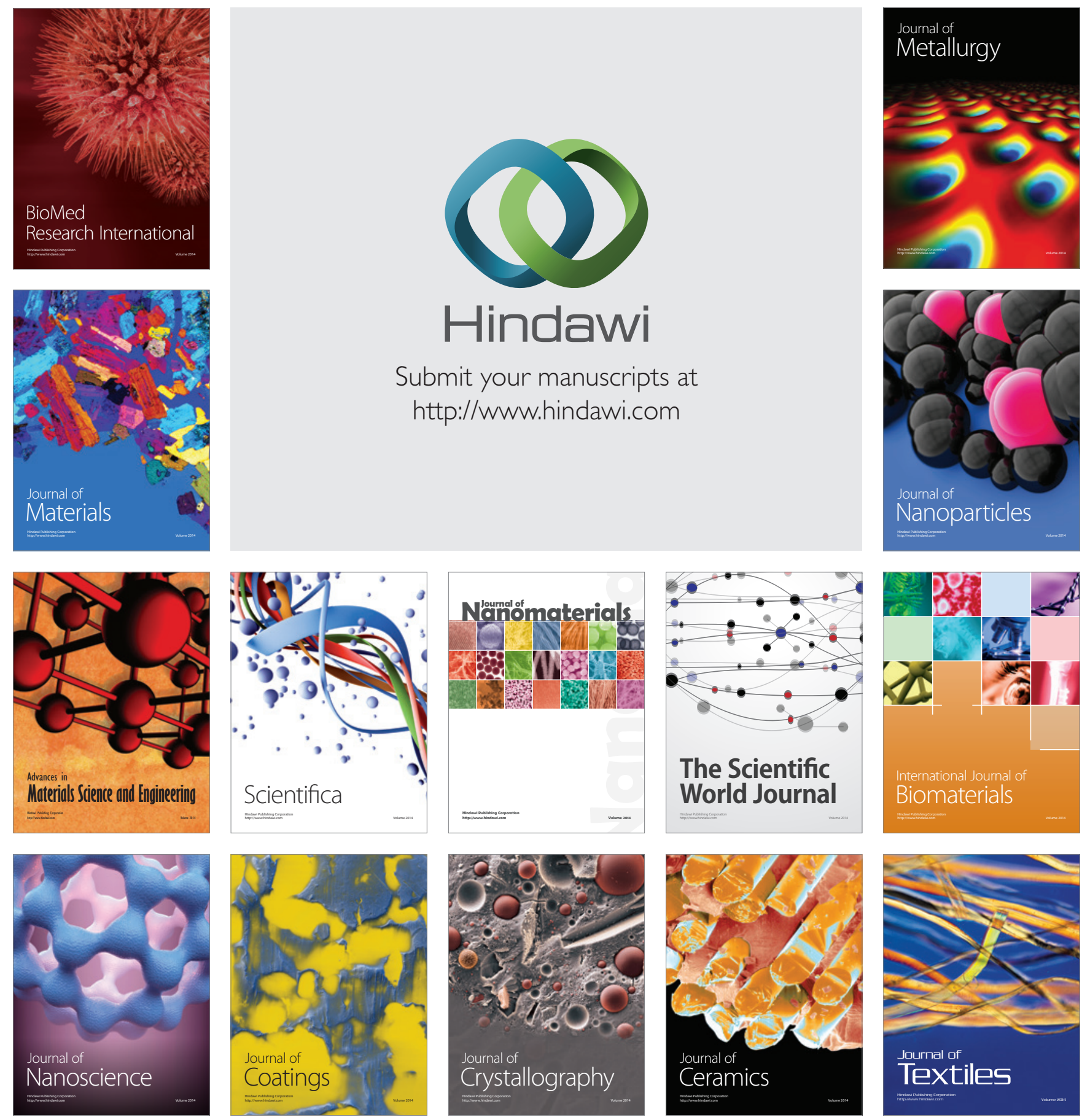